\title{
Perspectivas para o mercado de títulos de dívida no Brasil ${ }^{\dagger}$
}

\author{
Luiz Fernando de Paula* \\ João Adelino de Faria ${ }^{* *}$
}

\begin{abstract}
RESUMO - Este artigo analisa os fatores condicionantes que estimularam e restringiram o crescimento do mercado de títulos de dívida privada no Brasil, assim como o crescimento recente deste mercado.
\end{abstract}

Palavras-chave: Mercado de títulos de dívida. Títulos corporativos. Dívida pública

\section{INTRODUÇÃO}

O objetivo principal deste artigo é analisar as características e operação do mercado de títulos corporativos privados no Brasil, seus condicionantes e possibilidades, suas regras de operação, instituições que nele operam, demandantes de recursos, instrumentos financeiros desenvolvidos, bem como apontar algumas perspectivas para o desenvolvimento deste mercado. Mais especificamente o objetivo é avaliar e entender os fatores condicionantes que estimularam ou restringiram o crescimento deste mercado no Brasil.

\section{PRINCIPAIS TENDÊNCIAS E CARACTERÍSTICAS DO MTD}

O mercado de títulos da dívida tem crescido substancialmente na economia mundial, em especial nos países em desenvolvimento, desde o início dos anos 1990. De modo geral, a experiência internacional mostra que os mercados de títulos públicos e títulos privados tendem a crescer, grosso modo, conjuntamente. Nos países desenvolvidos, contudo, o mercado de dívida privada cresce mais que o mercado de dívida pública, como é o caso dos EUA, onde se observa um deslocamento entre os dois mercados. Já nos países em desenvolvimento, os títulos públicos domésticos são os principais papéis emitidos, seguidos por títulos privados domésticos internacionais e títulos públicos internacionais. $\mathrm{O}$

\footnotetext{
† Este artigo resulta de uma pesquisa realizada pela FECAMP/UNICAMP/UFRJ, "Perspectivas da indústria financeira brasileira e o papel dos bancos públicos", com o apoio do BNDES.

* Professor da Faculdade de Ciências Econômicas da Universidade do Estado do Rio de Janeiro - FCE/UERJ. Pesquisador do CNPq. Endereço eletrônico: luizfpaula@terra.com.br

** Mestre em Economia pela Faculdade de Ciências Econômicas da Universidade do Estado do Rio de Janeiro FCE/UERJ. Pesquisador da Universidade do Estado do Rio de Janeiro - UERJ/CNPq. Endereço eletrônico: joao.adelino@hotmail.com
} 
desenvolvimento do mercado de títulos de dívida nos países em desenvolvimento, desde o final dos anos 1980, decorre de um conjunto de fatores, dentre os quais a estabilidade macroeconômica, as reformas estruturais, a liberalização financeira, a introdução de marcos regulatórios prudenciais e legislação apropriada.

$\mathrm{Na}$ América Latina, o mercado de títulos de dívida cresceu significativamente nos últimos anos - a relação títulos de dívida/PIB passou de 17\% em 1990 para 35\% em 2004 (contra 23\% e 43\% dos países asiáticos em desenvolvimento no mesmo período), mas apresenta as seguintes características: predominam emissões de títulos públicos (25\% do PIB em 2004), os títulos são essencialmente de curto prazo (60\%), a maturidade da dívida é relativamente baixa e as operações em mercados secundários são pouco relevantes.

O Brasil é, entre os países latino-americanos, aquele com maior mercado de títulos de dívida, em termos absolutos e relativos, mas com larga dominância de títulos públicos. Em 2005 o estoque de títulos de renda fixa no Brasil (não incluindo títulos emitidos por instituições financeiras) correspondia a 74\% do PIB, enquanto que na Argentina, Chile, Colômbia e México eram de 33\%, 35\%, 32\% e 21\%, respectivamente.

No mercado de títulos de dívida corporativa no Brasil, destacam-se como principais papéis e instrumentos as debêntures (título corporativo de médio prazo emitido em geral por empresas de grande porte) e notas promissórias (título corporativo de curto prazo), sendo que nos anos 2000 adquiriram alguma importância novos instrumentos de securitização - os Fundos de Investimento de Direitos Creditórios (FIDC) e Certificados de Recebíveis Imobiliários (CRI) - que são lastreados em recebíveis e emitidos principalmente por empresas de médio porte.

Vários fatores microrregulatórios impactaram o mercado de valores mobiliários emitidos pelas empresas brasileiras. De fato, várias medidas vêm sendo adotadas para estimular o MTD privada, proporcionando mais segurança, ordenamento e transparência do mercado, incluindo, entre outras, fim da proibição à emissão de debêntures pelas sociedades de arrendamento mercantil, concessão de faculdade ao conselho de administração da empresa de capital aberto para deliberar sobre a emissão de debêntures simples, e determinação de que as ofertas públicas deverão ser realizadas em condições que assegurem tratamento equitativo aos destinatários e aceitantes das ofertas. A criação de instrumentos de securitização - em especial CRI e FIDC - disponibilizou novos mecanismos de financiamento das empresas, voltados em particular para médias empresas e bancos de porte médio. 
A evolução do MTD privada no Brasil esteve fortemente influenciada tanto pelo contexto macroeconômico da economia brasileira quanto pelas mudanças regulatórias feitas pelo governo. No caso do mercado de títulos de dívida privada, os subperíodos podem ser delineados em função de mudanças no contexto macroeconômico: 1990-1994 (alta inflação); 1995-1998 (estabilização com o Plano Real); 1999-2003 (instabilidade macroeconômica); 2004-2007 (estabilidade e crescimento); 2008 (crise financeira). No período 1990-1994 o MTD privada era pouco desenvolvido, com forte predomínio de emissão de debêntures, cujo volume era baixo e oscilatório, uma vez que a predominância de um comportamento curtoprazista, típico de um ambiente de alta inflação, inviabilizava dívidas em um horizonte temporal mais dilatado. Já o período 1995-1998, auge do Plano Real, houve um crescimento tanto do mercado de títulos corporativos de dívida (volume médio de $\mathrm{R} \$ 37$ bilhões, em valores de dez/2008, contra $\mathrm{R} \$ 14,4$ bilhões de emissão primária de ações) quanto no volume de emissões externas de empresas brasileiras, cujo total de média emissão foi de US\$ 24,4 bilhões no período. No período 1999-2003 o mercado de títulos privados - doméstico e externo - refluiu por conta da maior instabilidade macroeconômica do período (com destaque para duas crises cambiais, uma no início de 1999 e outra ao final de 2002), embora de modo desigual, já que em determinados momentos o mercado doméstico compensou a retração do mercado externo. O período 2004/07, por sua vez, foi favorecido tanto pela maior estabilidade e crescimento da economia brasileira quanto por fatores regulatórios, como, por exemplo, medidas simplificadoras para emissão de debêntures e criação (no período anterior) de instrumentos de securitização. Este último período mostrou que a maior estabilidade macroeconômica (crescimento do PIB, inflação sob controle, dívida pública declinante etc.) melhorou as condições de emissão dos títulos de dívida, com prevalência de debêntures e com alongamento nos prazos de emissão. Por fim, o ano de 2008 é marcado pelo contágio da crise financeira internacional, que se fez sentir mais fortemente a partir de outubro de 2008. O volume de emissão de debêntures se contraiu fortemente a partir do segundo trimestre deste ano, sendo apenas parcialmente compensado pela emissão de ações e de notas promissórias, que respondem juntos por quase 45\% das emissões no ano (Tabela 1).

Algumas características gerais do mercado de debêntures no período recente podem ser destacadas: prazo médio ainda relativamente baixo (de modo geral de 4 a 7 anos em média em 2000-2008); predominância de debêntures indexadas a taxa DI a partir de 1999; concentração das emissões em poucas empresas - em 2004-2008, as 8 maiores empresas emissoras representaram 53\% do total do valor das emissões; mercado secundário pouco 
denso (o volume de debêntures no mercado secundário representou apenas 3,7\% em média do total incluindo debêntures e ações no período 2004-2008); predominância em 1999-2008 de destinação de recursos para capital de giro, alongamento de perfil de endividamento e aquisição de bens de arrendamento ${ }^{1}$. No caso dos FIDCs observa-se que as principais modalidades de ativos-lastro da emissão têm sido recebíveis comerciais e financiamento de veículos, enquanto que as atividades econômicas que mais utilizam este instrumento de securitização - usado frequentemente por empresas e bancos de médio porte - foram intermediação financeira e indústria de transformação.

TABELA 1 - EMISSÕES DOS TÍTULOS E VALORES MOBILIÁRIOS

\begin{tabular}{|c|c|c|c|c|c|c|c|c|c|}
\hline & Ações & $\begin{array}{c}\text { Debên- } \\
\text { tures }\end{array}$ & $\begin{array}{l}\text { Quotas } \\
\text { de FII }\end{array}$ & $\begin{array}{l}\text { Notas } \\
\text { promis- } \\
\text { sórias }\end{array}$ & CRI & $\begin{array}{c}\text { Quotas } \\
\text { de FIDC }\end{array}$ & $\begin{array}{c}\text { Quotas de } \\
\text { fundos de } \\
\text { invest. em } \\
\text { partip. }\end{array}$ & Outros & Total \\
\hline \multicolumn{10}{|c|}{ Valores médios do período (R \$ milhões de dez/2008)* } \\
\hline $1995 / 1998$ & $14.393,3$ & $24.339,3$ & 424,7 & $12.548,4$ & 0,0 & 0,0 & 0,0 & 526,1 & $52.231,8$ \\
\hline $1999 / 2003$ & $2.919,5$ & $19.251,8$ & 786,5 & $11.194,3$ & 295,9 & 494,0 & 35,4 & 768,9 & $35.746,4$ \\
\hline $2004 / 2007$ & $16.578,3$ & $49.690,6$ & 396,6 & $5.868,7$ & $1.339,8$ & $10.909,5$ & $8.830,5$ & 608,8 & $94.222,8$ \\
\hline 2008 & $32.658,5$ & $39.948,2$ & 531,3 & $26.382,0$ & 955,0 & $10.416,5$ & $20.574,4$ & 829,4 & $132.295,4$ \\
\hline \multicolumn{10}{|c|}{ Participação relativa (\%) } \\
\hline $1995 / 1998$ & 27,6 & 46,6 & 0,8 & 24,0 & 0,0 & 0,0 & 0,0 & 1,0 & 100,0 \\
\hline $1999 / 2003$ & 8,2 & 53,9 & 2,2 & 31,3 & 0,8 & 1,4 & 0,1 & 2,2 & 100,0 \\
\hline $2004 / 2007$ & 17,6 & 52,7 & 0,4 & 6,2 & 1,4 & 11,6 & 9,4 & 0,6 & 100,0 \\
\hline 2008 & 24,7 & 30,2 & 0,4 & 19,9 & 0,7 & 7,9 & 15,6 & 0,6 & 100,0 \\
\hline
\end{tabular}

FONTE: CVM. Elaboração própria.

NOTA: * Valores deflacionados pelo IGP-DI centrado.

Os principais demandantes de títulos de dívida corporativa no Brasil têm sido os fundos de investimento e os fundos de pensão. Destacam-se, em particular, os fundos de investimento, que cresceram bastante no período recente, sendo que a indústria de fundos se diversificou, com diminuição do peso relativo ao longo do tempo dos fundos de renda fixa e DI e crescimento em contrapartida dos fundos multimercado, fundos de ações e previdência, mas ainda com a predominância dos fundos de renda fixa e DI (45\% do total do patrimônio líquido dos fundos em dezembro de 2007). No que se refere às suas aplicações, predominam as aplicações em títulos públicos federais e operações compromissadas em títulos públicos, tendo havido a partir de 2005 alguma diversificação para aplicações em ações e CDB/RDBs, sendo que a aplicação em debêntures cresceu, mas manteve-se relativamente baixa (cerca de $4 \%$ do total das carteiras dos fundos). Há uma boa sobreposição entre as aplicações dos fundos de investimento e fundos de pensão, uma vez que uma boa parte das aplicações destes

\footnotetext{
${ }^{1}$ Em particular, em 2004-2007, a emissão de debêntures foi em parte “contaminada” pelas empresas de leasing (arrendamento mercantil), frequentemente integrante de um conglomerado financeiro. As informações sobre ramos de atividade e destinação de recursos devem ser vistas com cautela, dada a precariedade das mesmas.
} 
últimos é feita através de fundos de investimento. $\mathrm{O}$ ativo dos fundos de pensão cresceu sobremaneira a partir de 2003, com destaque para as entidades de patrocínio público, sendo que há predominância na composição de carteira nas aplicações em renda fixa (fundos de investimento e títulos públicos), o que é explicado em parte pela combinação de liquidez e rentabilidade que tem sido proporcionada pelos títulos públicos no Brasil.

\section{PRINCIPAIS CARACTERÍSTICAS E CONDICIONANTES DA EXPANSÃO DE} 2004-08

No período 2004-08, favorecido pelo cenário externo favorável - boom de commodities e elevada liquidez no mercado financeiro internacional - a economia brasileira teve um crescimento econômico médio de 4,6\% bem superior a média de 1,9\% do período 1999-2003. O contexto internacional favorável permitiu que o crescimento econômico fosse realizado sem ser contido pela restrição externa. A valorização na taxa de câmbio ajudou na redução da taxa de inflação que caiu de 9,3\% em 2003 para 3,1\% em 2006. O crescimento econômico combinado com certa redução na taxa Selic permitiu que a relação dívida pública/PIB caísse de 52,4\% em 2003 para 36,0\% em 2008. O período finaliza com os impactos da crise financeira internacional sobre a economia brasileira, em função da dupla restrição de liquidez - saída de capitais de não-residentes e desaceleração no crescimento do crédito doméstico que se fez sentir ao longo do ano de 2008, em particular a partir da quebra do Lehman Brothers.

Como pode ser observado na Tabela 1 há um forte boom na emissão de títulos e valores privados - ações, debêntures e notas promissórias. A média anual de emissão de títulos e valores em 2004-07 foi de R \$ 94,2 bilhões contra a média anual de R \$ 35,7 bilhões em 1999-2003. Este boom no mercado de títulos privados é resultado de um conjunto de fatores, que inclui o maior crescimento econômico, certa redução na taxa de juros (que estimula a busca de maior rentabilidade por parte do investidor), mudanças regulatórias (que já vinham ocorrendo no período anterior), estímulo fiscal ao alongamento nos prazos dos fundos de investimento, além da emissão de debêntures por parte de empresas de leasing. No período analisado foram bastante utilizados os mecanismos de green shoe e lote suplementar, permitidos a partir da Instrução CVM no. 400, que estimularam o acesso das empresas ao mercado de capitais, ao possibilitar adaptar o montante total das emissões à demanda existente por títulos e, ao mesmo tempo, beneficiar-se eventualmente de melhores condições de juros e risco. 
No período 2004-07 houve forte crescimento na emissão de debêntures, cuja emissão anual média foi de R\$ 49,7 bilhões contra R\$ 19,3 bilhões em 1999-2003, crescimento este que veio acompanhado do aumento no prazo médio de emissão de 4,5 anos em 2003 para 7,2 anos em junho de 2008. A predominância de debêntures indexadas à taxa DI (mais de $90 \%$ do total) reflete a aversão dos investidores em carregar o risco de mercado vis-à-vis a instabilidade histórica da (alta) taxa de juros no Brasil. Quanto ao ramo de atividades, houve uma forte prevalência de arrendamento mercantil (67,0\% do total em 20042008), seguido bem abaixo de empresas de administração e participações (10,7\%) e energia elétrica (7,5\%). As empresas de leasing abasteciam os bancos (que não podem emitir debêntures) do mesmo conglomerado que buscavam recursos livres de compulsório para ofertar mais crédito no mercado, em particular nas operações de financiamento de veículos ${ }^{2}$.

A forte desaceleração no mercado de debêntures a partir do $2^{\circ}$ trimestre de 2008 se deve a um conjunto de fatores, que inclui a instituição de compulsório para empresas de leasing, a elevação na taxa de juros no primeiro semestre, a concorrência das CDBs, a incerteza quanto à crise financeira internacional, entre outros. Neste ano há parcialmente uma substituição de emissão de debêntures por notas promissórias.

\section{FATORES QUE LIMITAM OU ESTIMULAM O MTD PRIVADA NO BRASIL}

Segundo a teoria da preferência pela liquidez, a demanda dos ativos financeiros não monetários é influenciada fundamentalmente pelo estado de expectativas dos agentes, sob condições de incerteza, que define as condições de retorno (ajustado ao risco) e de liquidez destes ativos. Deste modo, quanto maior a incerteza percebida mais os agentes passam a valorizar os atributos de maior liquidez dos ativos em detrimento da rentabilidade, e com isto aumenta o prêmio de risco cobrado para aquisição de títulos de maior maturidade e/ou de baixa liquidez. Alternativamente, quanto menor a incerteza percebida, maior a propensão ao risco do investidor, sendo os atributos de rentabilidade privilegiados em relação à liquidez dos ativos financeiros. Tais "preferências" determinam não só a composição dos portfólios dos agentes investidores como o prêmio de risco que cobram para adquirir ativos financeiros menos líquidos.

Uma das implicações importantes desta abordagem teórica para análise do MTD é que as condições de oferta de títulos corporativos são, em boa medida, determinadas pela

\footnotetext{
${ }^{2}$ Esta operação ficou conhecida no mercado como "Zé com Zé”.
} 
percepção de risco e retorno dos investidores. Como já sugerido, o ambiente macroeconômico e a política econômica - crescimento da economia, inflação, política de juros, movimento da taxa de câmbio etc. - têm um papel fundamental na determinação da demanda e oferta por títulos e nas condições (montante emitido, remuneração, maturidade etc.) sob as quais os títulos são ou poderão ser emitidos. Do lado do ofertante de títulos corporativos (a empresa), o crescimento econômico (que aumenta a possibilidade de aumento de vendas e lucros, permitindo gerar renda para saldar compromissos financeiros assumidos) e o comportamento das taxas de juros (custo do crédito bancário e custo de oportunidade do capital) e de câmbio (preço fundamental na determinação das relações externas da empresa) são fundamentais para definir a oferta de títulos. Do lado dos demandantes de títulos, além do ambiente macroeconômico em geral, a política de juros do banco central afeta de forma importante o grau de aversão a riscos dos investidores: uma expectativa de juros futuros elevados aumenta a preferência por moeda e ativos de alta liquidez, enquanto que uma expectativa de queda aumenta a preferência por títulos de renda fixa e variável.

A existência de mercados secundários organizados para títulos privados também é um fator importante no desenvolvimento do mercado de títulos ao proporcionar maior liquidez aos ativos financeiros de maturidade mais longa e, com isto, podendo estimular (ou, no caso da ausência de mercados secundários, desestimular) a demanda por tais ativos. Por outro lado, deve-se considerar a relação entre dívida pública e dívida privada de empresas não-financeiras, já que o desenvolvimento do primeiro permitiria o desenvolvimento do segundo, ao estabelecer uma infraestrutura necessária para a comercialização de títulos de dívida. Ao mesmo tempo o mercado de dívida pública pode estabelecer um benchmark para o mercado privado, ao permitir formar uma curva de rendimentos que contribua para identificar o custo de oportunidade de fundos para os investidores e poupadores.

No caso do Brasil devem-se considerar algumas características peculiares do país, que têm implicações importantes do ponto de vista do desenvolvimento do MTD privada. Em primeiro lugar, o histórico de instabilidade macroeconômica que marcou a economia brasileira desde os anos 1980 é o fator principal na formação do perfil de dívida de curto prazo e com parcela significativa constituída por títulos atrelados à taxa Selic e a DI. As incertezas que têm cercado o comportamento da economia brasileira, caracterizado por ciclos de "stop and go", têm sido grandes o suficiente para desestimular horizontes maiores de expectativas para investidores e empresas no país. Em segundo lugar, em que pese o elevado desenvolvimento do mercado de títulos públicos, a existência de uma boa parte da dívida 
pública sob a forma de títulos indexados a Selic $\left(\operatorname{LFTs}^{3}\right)$, herança do período de alta inflação, acaba por inibir e deformar o MTD privada no Brasil, uma vez que a combinação riscoretorno dos títulos públicos é uma das melhores entre os ativos financeiros, por combinar baixo risco, alta liquidez e rentabilidade. Isto resulta em uma alta demanda por aplicações nos chamados fundos de depósitos interbancários (DI) ou diretamente por títulos públicos federais. Portanto, a forma de gestão da dívida pública no Brasil acaba sendo determinante nas "preferências" do investidor, ao moldar uma combinação risco-retorno que privilegia aplicações indexadas a taxa Selic e sua "prima" taxa DI ou aplicações de renda fixa de curto prazo.

Neste contexto, os emissores de títulos corporativos privados prefixados de maturidade mais longa, para emitirem tais papéis, teriam que pagar um prêmio de risco extremamente elevado para compensar sua baixa liquidez, seu maior risco de mercado (face à baixa duration dos títulos públicos) e maior risco de default, o que tornaria muito cara e/ou com maturidade muito curta sua emissão, o que poderia ser incompatível com a rentabilidade no negócio de uma firma produtiva. Assim, as firmas acabam emitindo debêntures ou FIDCs com remuneração média e prazo médio, mas com características relativamente semelhantes às LFTs (remuneração vinculada à taxa DI), ainda que com um prêmio de risco maior do que destas.

\section{PERSPECTIVAS}

Ao se analisar as perspectivas futuras do mercado de título de dívida (MTD) privada devem-se considerar três dimensões de certa forma interconectadas: a evolução do contexto macroeconômico, o contexto regulatório e a gestão da dívida pública.

A primeira dimensão - contexto macroeconômico - é importante uma vez que o mercado de capitais no Brasil tem tido um comportamento pró-cíclico, desenvolvendo-se em períodos de maior crescimento e estabilidade, e contraindo em períodos de desaceleração cíclica e instabilidade macroeconômica. Como já foi assinalado, uma das características da economia brasileira tem sido seu comportamento "stop and go" e uma tendência a um crescimento baixo. O ambiente de instabilidade macroeconômica afeta o volume e as condições de emissão

\footnotetext{
${ }^{3}$ As LFTs têm duration de um dia ou zero, dado que o título remunera o valor aplicado pela taxa de juros a cada dia, ou seja, é como se o investidor estivesse a cada dia reaplicando o principal e o juro ganho à nova taxa de juros do mercado. Assim, o investidor tem, a princípio, a alternativa de resgatar a dívida no dia-a-dia, possuindo assim a garantia de liquidez imediata. O que torna atraente as LFTs é a possibilidade de reposicionamento diário frente à taxa de juros, além de oferecer frequentemente o benefício de taxas de juros nominal e real generosas.
} 
primária de títulos de dívida privada no Brasil, ao aumentar o risco de mercado (perda de valor de um título perante a uma elevação na taxa de juros) e o risco de inadimplência. Expectativas altistas quanto à taxa de juros elevam o prêmio exigido pelos demandantes por títulos de maturidade mais longa e aumentam a demanda por títulos indexados ao DI (o que coloca nas mãos da firma o problema do risco de taxa de juros). Portanto, tanto a volatilidade quanto o nível da taxa de juros afetam decisivamente as condições de oferta e demanda de títulos corporativos no Brasil. Por exemplo, uma taxa de juros mais baixa e estável pode estimular a demanda por títulos de dívida prefixados, mais adequados do ponto de vista da redução da fragilidade financeira das firmas.

O boom do mercado de capitais no período 2004-2007 mostrou como um ambiente econômico mais favorável acaba estimulando o desenvolvimento do mercado de títulos de dívida e de capitais em geral: não só o volume de emissão de títulos de dívida privada cresceu como se propiciou um alongamento em seus prazos. É importante assinalar que o mercado de capitais é estimulado pelo, e estimula o, crescimento econômico, ou seja é causa e efeito, já que cumpre um papel importante do ponto de vista do financiamento das empresas de médio e grande porte. Apesar do autofinanciamento via lucros retidos ser a principal forma de financiamento dos investimentos e da produção no Brasil, as firmas tendem a buscar - num segundo momento por ocasião de um processo de crescimento econômico mais sustentável recursos externos a firma por ocasião da expansão de sua atividade produtiva. Assim, a gestão de uma política macroeconômica estabilizadora - viabilizando taxas de juros mais baixas e estáveis e estimulando o crescimento da demanda agregada na economia (e aumentando consequentemente os lucros das empresas) - tem um papel fundamental no crescimento mais robusto do mercado de títulos de dívida no Brasil. Trata-se de uma condição necessária, ainda que possa não ser suficiente, para o desenvolvimento deste mercado. A redução da taxa de juros ocorrida no primeiro semestre de 2009 estimulou, na margem, a diversificação de portfólio dos investidores - em particular dos investidores institucionais como fundos de pensão, fundos de investimento e seguradoras - para absorver títulos de maior risco em relação a títulos públicos ${ }^{4}$, mas tanto a existência de um "piso" para tal redução em função da política monetária adotada pelo BCB quanto as expectativas altistas em relação a taxa de juros

\footnotetext{
4 Segundo reportagem no jornal Valor (30/10/2009, p.C8), "há duas semanas, no congresso dos fundos de pensão, em Curitiba, o discurso dos fundos de pensão era um só: como buscar alternativas de investimento aos títulos públicos. A taxa de retorno dos Certificados de Depósito Bancário (CDB) também vem perdendo atratividade. As seguradoras, que sempre garantiram o lucro com ganhos financeiros, também sofrem agora com a queda do juro".
} 
para 2010 parecem colocar um limite nesta tendência.

Mudanças regulatórias que estimulem o mercado de títulos de dívida - por parte das autoridades regulatórias (CVM) e autorregulatórias (ANDIMA e ANBID $^{5}$ ) - são importantes tanto do ponto de vista do mercado primário de títulos de dívida (como, por exemplo, medidas que busquem a simplificação das emissões e sua popularização, estimulando o aumento de demandantes desses títulos), quanto do ponto de vista da expansão de mercados secundários, através de medidas que estimulem a revenda de títulos. Por exemplo, podem-se considerar medidas que ajudem a criação de uma curva de rendimentos de títulos de dívida privado, como é o caso da "publicização" do cálculo de preços indicativos de debêntures por parte da ANDIMA, visando tornar comparáveis os rendimentos de títulos privados com maturidades semelhantes. Uma agenda interessante para discussão seria identificar medidas que poderiam ser adotadas para "popularizar" a oferta de títulos nos bancos varejistas, através de fundos específicos lastreados com esses papéis. Neste sentido, os bancos púbicos varejistas poderiam ajudar, por exemplo, diminuindo o ticket de entrada, isto é, o valor mínimo de aplicação em títulos corporativos.

Ainda do ponto de vista regulatório, uma importante medida a ser adotada é a implementação de tributação que estimule a aplicação de recursos mais a longo prazo. $\mathrm{Na}$ legislação atual, a tributação do imposto de renda (IR) incide nos fundos de curto prazo com uma alíquota de 22,5\% sobre os rendimentos até 180 dias e 20\% acima de 180 dias, enquanto que nos fundos de longo prazo e títulos de renda fixa 22,5\% até 180 dias, 20\% de 181 a 360 dias, $17,5 \%$ de 361 a 720 dias, e 15\% acima de 720 dias. Neste particular, sugere-se uma tributação regressiva mais efetiva do ponto de vista do estímulo ao alongamento dos prazos dos títulos de dívida, através da cobrança de imposto ainda mais alto para investimentos de curto prazo (por exemplo, aumentando a alíquota para 30\% até 180 dias), reduzindo a alíquota conforme o prazo de aplicação.

Por último, mas não menos importante, mudanças no perfil da dívida pública podem exercer um papel crucial no desenvolvimento do mercado de títulos de dívida privada no Brasil, tanto no que se refere ao mercado primário quanto ao mercado secundário. A existência de títulos indexados à Selic acaba funcionando com um fator inibidor tanto do mercado primário de títulos privados, por conta da competição de um papel livre de risco de mercado e risco de default, quanto do mercado secundário de títulos, uma vez que a

\footnotetext{
5 As duas instituições integraram suas atividades em outubro de 2009, criando a ANBIMA - Associação Brasileira de Entidades dos Mercados Financeiros e de Capitais.
} 
prevalência de tais títulos (indexados à Selic) desestimula o desenvolvimento do mercado secundário de títulos públicos (que poderia, por sua vez, fomentar o desenvolvimento do mercado secundário de títulos privados). De fato, o que estimula a atuação do investidorespeculador neste mercado é justamente a possibilidade de especular em relação às variações do valor do título. De fato, observa-se uma melhoria no perfil da dívida pública em 20042007, passando os títulos prefixados de 16,8\% do total em junho de 2004 para 37,3\% em dezembro de 2007, mas caindo ao longo de 2008 no quadro do contágio da crise financeira internacional. Portanto, a melhoria no perfil da dívida pública, com diminuição de títulos indexados à Selic e crescimento de títulos prefixados, que pode ser propiciada pela queda na taxa de juros de curto prazo e melhoria no contexto macroeconômico em geral, teria efeitos benéficos tanto do ponto de vista do desenvolvimento do mercado primário (dada a contaminação dos títulos privados por títulos públicos indexados à Selic) quanto do mercado secundário, já que espera-se que o desenvolvimento do mercado secundário de títulos públicos ajude a fomentar o mercado secundário de títulos privados. 
